\title{
Aspectos psicológicos no uso de afrodisíacos
}

Zenilce Vieira Bruno*

Para a boa marcha dos estudos em Sexologia é fundamental que se caracterize o conceito dos afrodisíacos, separando-se suas ações geniturinárias, psíquicas, neurológicas, hormonais e vasculares. Neste texto vamos nos ater aos aspectos psicológicos envolvidos no uso dos mesmos.

Os Afrodisíacos têm como principal característica a problemática de sua variância, pois o mesmo "agente", instigante para uns, pode ser um elemento de bloqueio para outros. Nesses casos torna-se antiafrodisíaco, inibindo o desejo sexual. Ainda assim esse efeito difere daqueles observados pela ação dos Alteradores Psíquicos, mais conhecidos como alucinógenos, que funcionam provocando modificações na mente do usuário.

Existe uma grande diferença entre os alucinógenos e os afrodisíacos. Os primeiros permitem ou auxiliam estados alterados da consciência do tipo místico ou mágico, resultantes das alterações neurológicas provocadas por suas substâncias. Já os afrodisíacos parecem facilitar ou induzir estados alterados do tipo eostáticos, ou seja, aqueles que sugerem uma suscetibilidade e uma expansão da mente para a busca do êxtase sexual. A finalidade dos afrodisíacos é incitar ao amor carnal.

* Psicóloga Clínica, socióloga, orientadora educacional.

Recebido em 10.01 .00

Aprovado em 20.01 .00 
Embora não haja cientificidade na comprovação do uso de drogas específicas que aumentem o desejo sexual, alguns componentes químicos são conhecidos por provocar excitabilidade e sensibilizar os órgãos envolvidos na resposta sexual humana. O popular Ecxtasy, muito usado pelos jovens de grandes centros urbanos como São Paulo e Rio de Janeiro, é conhecido pelo seu efeito anfetamínico potente, provocando no usuário a sensação de excitabilidade, energia e alegria que facilmente remetem aquelas experimentadas durante relações sexuais prazerosas. Esta euforia anfetamínica é reconhecida popularmente como "afrodisíaca" e assim como qualquer outra droga usada invasivamente, sendo inalada, fumada, ou ingerida, esta também pode causar dependência psíquica. Há ainda um outro fator importante que é a tolerância, o fenômeno do organismo em necessitar, cada vez mais, de maiores quantidades do mesmo elemento, para se obter resultados idênticos.

O uso de substâncias alucinógenas para o incremento das sensações eróticas durante um encontro amoroso é um hábito muito antigo. Muitos relatos de estudos antropológicos com comunidades indígenas registram a utilização de plantas, ervas, raízes e compostos, nas mais variadas formas de administração, com o objetivo de transformar o sexo num ato sagrado e divino, portanto passível de alterações psíquicas, inclusive delirantes e alucinatórias. Devido as distinções culturais, o uso de drogas alucinógenas em nossa cultura geralmente tem caráter ilícito e muitas possuem efeitos deletérios a saúde física e psíquica de seus usuários. No entanto, algumas substâncias conhecidas como "afrodisíacas" como o pó de guaraná e a catuaba, são revestidos de crendices populares o que torna a sua utilização em caráter lúdico e misterioso. De qualquer forma as pessoas que ingerem essas substâncias em geral, buscam os mesmos objetivos: incitar o desejo sexual, atrair e provocar a libido do(a) parceiro(a), aumentar a energia física e intensificar o ato sexual. Variando no entanto em sua utilização o resultado de acordo com a pessoa, momento, idade, situação ou meta.

É necessário que todos aqueles que se apoiam nos Afrodisíacos compreendam que o elemento liberador da sexualidade está, não na substância tida como afrodisíaca, mas dentro da própria mente. A droga só libera, não podendo criar nada que já não exista. Portanto, é importante ter sempre em mente que o poder de experimentar vida sexual plena e satisfatória está em cada um. Os Afrodisíacos podem servir apenas como um "gatilho" para detonar esse processo, entre os muitos que existem. O importante é estar atento para os "modismos" que promovem o uso de determinadas drogas com finalidades apenas comerciais.

A libido pode ser comparada com o tempo. Como o clima, o impulso sexual humano é propenso a mudanças conforme as estações, neste caso originadas pelos diversos períodos e situações da vida, ao invés dos ciclos anuais. Embora os meteorologistas entendam muito sobre os processos físicos que influenciam a formação do tempo, o número de variáveis é tão 
grande que, mesmo os mais sofisticados aparelhos de medição meteorológica não podem prever com segurança como o tempo será amanhã. É igualmente difícil predizer os níveis de excitação sexual nos indivíduos, não apenas pela influência dos muitos aspectos envolvidos, mas também porque sabemos pouco sobre os processos básicos que afetam a libido.

Existem vários motivos para compreendermos a limitação do nosso entendimento dos caminhos e descaminhos do desejo. Muitos dos fatores que afetam nosso impulso sexual estão fora do nosso controle, já que a marca da sexualidade humana é o papel central desempenhado também pelo parceiro e não apenas as características exibidas pela própria pessoa e seu comportamento cotidiano. Outra razão é que algumas das variáveis que afetam este impulso sexual, incluindo os processos corporais internos, estão além da nossa percepção consciente.

De fato, não existe qualquer substância que aumente o desejo sexual em todas as pessoas. Entretanto, há crescente evidência de que algumas pessoas com redução da libido podem ser auxiliadas pela terapia medicamentosa, sendo os medicamentos em questão a classe de hormônios esteróides conhecidos como androgênios.

Existe uma regra simples na previsão do tempo; se o céu está nublado, talvez chova e talvez não, dependendo das outras condições. Mas se não há nuvens no céu, é muito improvável que chova. Da mesma forma uma pessoa, cujos níveis circulantes de androgênio são normais, pode atingir a excitação sexual ou não, dependendo das circunstâncias que a cercam. Mas uma pessoa, sofredora de níveis circulantes de androgênio gravemente reduzidos, tem muito menos probabilidade de experimentar excitação sexual, não importando quão favoráveis estejam as circunstâncias.

A busca da melhora da sexualidade é tão antiga quanto a história da própria humanidade. Outras práticas eram usadas na idade média para ter, manter e conseguir a pessoa amada. Pode-se afirmar que os romanos foram os grandes "macumbeiros" da antigüidade. Inúmeros fetiches e magias foram e são usadas no ritual do sexo. Isso mostra a importância do sexo na vida humana e o comportamento do próprio homem na sua vida quando ele verifica que o exercício da sua sexualidade está limitado aos níveis de sua idealização. Portanto, não é de admirar que os seres humanos, há longo tempo, venham buscando formas fáceis e até mágicas de modificar e geralmente elevar a libido. Muitas substâncias foram anunciadas como tendo propriedades afrodisíacas com capacidade de realçar o impulso sexual.

Entre todas as práticas, as plantas são as mais usadas e tentadas como afrodisíacas ou eróticas, tendo a melhor aceitação nas diversas culturas e em todos os tempos, tidas como as substâncias afrodisíacas que têm mais eficácia e ação real para homens e mulheres.

No Brasil, especialmente no norte e nordeste, as famosas "garrafadas regionais" tidas como propriedades afrodisíacas, representam um folclore que vem sendo transmitido através de gerações. A catuaba é, indubitavel- 
mente, a mais famosa de todas as plantas afrodisíacas brasileiras e apreciada pelas populações locais há várias gerações. Esta estimada erva da floresta tropical brasileira é louvada pelos índios Tupi, sendo um excelente fortificante do sistema nervoso e aumentando a libido do homem. A casca da catuaba funciona como um estimulante do sistema nervoso. É usada como afrodisíaco e tônico para o órgão genital masculino. Segundo estudos ela age efetivamente com a impotência masculina como também auxilia nos casos de fadiga em geral, ajudando também a eliminar a inquietude durante o sono, nos casos de insônia dos hipertensos e na falta de memória. A catuaba normalmente é consumida como um chá feito da casca deste pequeno arbusto.

Desde sempre, a humanidade tem recorrido as substâncias, truques, magias e jogos para a estimulação do desejo amoroso e da fertilidade, ocorrências essas, que por vezes foram classificadas apressadamente como atitudes perversas por estudiosos do comportamento humano. No entanto sabemos hoje que a busca do prazer sexual é um componente da boa saúde, inspira a criação e faz parte do caminho da alma. Deve ser dissociado dos sentimentos de culpa ou segredo, porque o amor sagrado e o profano provém da mesma fonte e supõe-se que os deuses celebravam também o prazer humano.

Diante da falta de informações científicas sobre a eficácia do uso de substâncias para estimular o desejo sexual, devemos registrar que a percepção para o prazer erótico é conhecida como afrodisía, e esta depende exclusivamente das potencialidades do indivíduo e suas variações, compreendendo todos os órgãos do sentido e é classificada em: afrodisia auditiva, visual, olfativa, tátil e gustativa. Portanto lembramos que a música, determinados sons e ruídos, palavras ternas ou picantes podem ser estimulantes afrodisíacos para alguns, enquanto o silêncio pode ser bálsamo para outros. Assim também as fragrâncias cítricas podem ser enebriantes para uns, incômodas para outros e mesmo insignificantes para terceiros. A mesma observação serve para o estímulo obtido através da degustação de sabores, visualização de imagens e percepção tátil.

Infelizmente o que temos observado é que a criatividade para despertar a busca pela ativação dos órgãos do sentido para a apetência sexual tem sido baseada nos preceitos mercadológicos da sociedade de consumo e portanto empobrecido a descoberta individual das sensações de prazer.

Como a libido sempre se faz presente e na impossibilidade de a satisfazer-mos, vivemos obcecados pelo insaciável apetite cada vez mais forte; porém na pressa de devorar tudo, dissociamos o corpo da alma. Já não bastam uma carícia sutil, o prazer de pele contra pele ou compartilhar um pêssego, exigimos exaltação cósmica que de preferência esteja a venda nos balcões das farmácias da esquina, nas academias de ginástica e clínicas de estética. Na busca de alívio para o tédio elevamos a crueldade muitas vezes a categoria de arte ou de piada. 
É necessário anunciar de peito aberto, que o único afrodisíaco verdadeiramente infalível é o amor. Nada consegue deter a paixão acesa de duas pessoas apaixonadas. Neste caso, não importam os achaques da existência, o furor dos anos, o envelhecimento físico ou a mesquinhez de oportunidades; os amantes dão um jeito de se amarem porque, por definição, esse é seu destino.

\section{REFERÊNCIAS BIBLIOGRÁFICAS}

ABRAHÃO, J. A verdade sobre os afrodisíacos. Revista Safira Estrela da Primavera, 1996.

ALLENDE, I. Afrodite. Bertrand Brasil. Rio de Janeiro, 1998.

BRAGA, R. Plantas do Nordeste, especialmente do Ceará. Editora Universitária UFRN. Natal, 1960; p. 8-15.

BREEDLOVE, M. Liberando a libido. Revista da Organon sobre a mulher e a saúde, 1999; 24-30.

CHARAM, I. Há ações afrodisíacas nas plantas medicinais do Brasil? A Folha Médica. Editora Científica, 1987; 94(5): p. 303-309.

CHARAM, I. Tratamento farmacológico da impotência sexual. Revista Sexológica do Rio de Janeiro, 1982; 3(3): 12-17.

SANGIRARDI, J. Plantas eróticas. Codecri. Rio de Janeiro, 1984; p. 31-34.

WILSON, G. Um toque sensual. A arte de fazer amor. Limited, 1989. 